\title{
THE KIDNEY IN LEAD POISONING
}

BY

\author{
ZDENKO RADOŠEVIĆ*, MARKO ŠARIĆ†, TIHOMIL BERITIĆł
}

From the Institute for Medical Research, Yugoslav Academy of Sciences and Arts, Zagreb

(RECEIVED FOR PUBLICATION JUNE 28, 1960)

Kidney damage due to lead is still an interesting problem of industrial toxicology. In spite of abundant literature data, much still remains to be explained. There are controversial opinions, not only on the type of renal lesions due to lead, but also on whether lead affects the kidney at all.

In this paper our clinical observations on the effect of lead upon the kidney in 53 patients suffering from lead poisoning are presented. In 44 patients (40 men and four women) lead poisoning was due to occupation, and in nine (five men and four women) to the use of lead-glazed pottery. The length of exposure varied from two months to 35 years. In all cases the diagnosis of lead poisoning was made clinically and confirmed by laboratory tests.

Permanent changes in the form of chronic nephropathy were observed in only two patients. These were the two cases in which exposure to lead was the longest and most intense. Twenty-three patients showed functional renal lesions tending to normalize. In addition to the cases of organic nephropathy, blood pressure was persistently raised in one further patient; in two patients a raised blood pressure was observed only in the acute stage of poisoning.

On the basis of these findings we consider that lead intoxication can cause renal lesions. These lesions are for the most part functional and temporary. In cases of long and severe exposure and repeated lead intoxication, organic renal lesions seem possible. The disturbances of renal function observed in this study may be ascribed to disordered intrarenal circulation, due to the spastic effect of lead on intrarenal blood vessels, and to a direct toxic or indirect hypoxic effect of lead on the tubules.

When investigating renal function, we have observed that the timing of individual tests is of paramount importance. Some lesions are subject to changes in the natural course of lead poisoning, and unless this is borne in mind, apparently contradictory results may be obtained.

The question as to whether lead produces kidney damage has been discussed for nearly 100 years, and never answered satisfactorily. The problem is still important, both from theoretical and practical points of view, and in Yugoslavia in particular, where not only industrial workers but also peasants are exposed to lead comparatively often.

Published data on the effect of lead upon the

\footnotetext{
* Associate Professor of Medicine, Medical Faculty, University of Zagreb, Zagreb.

$\dagger$ Research Associate, Institute for Medical Research (incorporating the Institute of Industrial Hygiene), Yugoslav Academy of Sciences and Arts, Zagreb.

‡ Senior Research Associate, Recognized Teacher of Industrial Hygiene, Institute for Medical Research (incorporating the Institute of Industrial Hygiene), Yugoslav Academy of Sciences and Arts, Zagreb.

§ Assistant, Institute for Medical Research (incorporating the Institute of Industrial Hygiene), Yugoslav Academy of Sciences and Arts, Zagreb.
}

kidney are often contradictory. The earlier writers were convinced that lead caused kidney damage and did not hesitate to use a special nosologic term "lead kidney" (Bleiniere, nephropathia saturnina) as if it were an accepted fact (Lancereaux, 1881; Leyden, 1883; Gayler, 1887; Oliver, 1914; Volhard and Fahr, 1914). More recently authors, especially in America, are doubtful about the existence of such damage (Belknap, 1936; Mayers, 1947; Humperdinck, 1948; Johnstone, 1948; Greenfield and Gray, 1950).

The approach to the problem may have accounted for such divergent opinions: on the one hand, the lack of definite diagnostic criteria and reliable statistics on the frequency of the so-called lead nephropathy but an experience obtained by observations of a great number of persons with a long and severe exposure to lead and suffering 
from severe lead poisoning; on the other hand, more reliable modern diagnostic procedures based on well-developed renal function tests but little experience concerning long exposure to lead and severe lead poisoning.

There are modern writers who do consider kidney damage due to lead to be possible. Cantarow and Trumper (1944) drew attention to difficulties in the interpretation of results, and pitfalls in the assessment of the findings, especially those based on insufficiently checked clinical observations and post-mortem findings. Nevertheless, they considered that the opinion of the medical authorities who recorded manifest renal lesions due to lead should be taken into consideration. Lane (1949) attempted to explain the contradictory statements on this problem by studying workers' health and working conditions in Britain in the course of the industrial development of that country. In his opinion, the changing intensity of exposure to lead in the course of time may have accounted for great differences between former and present-day findings.

Bell, Williams, and Cunningham (1925) reinforced the belief that lead could produce renal lesions. For therapeutic purposes they administered colloidal lead solution intravenously to patients suffering from malignant tumours. Pronounced lesions of the renal tubular epithelium were observed. However, from the work of these authors, nothing can be concluded about the kidney changes which may occur in the course of a prolonged exposure to lead.

In connexion with the role of lead in the aetiology of kidney lesions special attention should be drawn to the investigations of Australian workers. As early as the first decade of this century a higher incidence of chronic nephritis was observed in Queensland, Australia than in other parts of the country. From the first observation it was believed that the disease was a late result of excessive lead absorption in childhood. The investigators dealing with this problem (Nye, 1933; Cilento, 1932; Murray, 1939) came to the conclusion that at least some of these cases of chronic nephritis could be attributed to the effects of lead. There was evidence of past lead poisoning in about a third of the cases examined. In the remaining cases, it was believed that subclinical lead poisoning might be responsible for the incidence of chronic nephritis, but there was no direct evidence to prove it. In later publications dealing with the same problem (Henderson, 1954; Henderson, 1955; Henderson and Inglis, 1957) the causal link between lead poisoning in childhood and chronic nephritis was again considered. In a comprehensive review, Henderson (1958) supported his opinion of the lead aetiology of Queensland chronic nephritis by the finding of a high percentage of renal disease in persons known to have had lead poisoning in childhood. There was a comparatively frequent history of childhood saturnism in the chronic nephritis group investigated, and bone lead content was raised significantly in the fatal cases of the same group. Henderson laid great emphasis on the fact that these findings occurred only in a group of cases which had been separated on the basis of clinico-pathological findings different from those common in renal disease of generally accepted aetiology, such as glomerulonephritis and pyelonephritis.

There is also considerable difference of opinion on the mechanism of the noxious effect of lead on the kidney and the pathogenesis of renal lesions. Both experiments on animals and clinical and histopathological studies on man have revealed different pathological changes, such as vasculopathy (Hoffa, 1883; Lancereaux, 1881; Leyden, 1883; Gayler, 1887; Volhard and Fahr, 1914; Brogsitter and Wodarz, 1922; Battaglia, 1927; Aiello, 1931; Wirtschafter, 1933; Micheli, 1935; Izar, 1941; Vigliani, 1950), primary tubular lesions (Jores, 1902; Flury, 1934; Beintker, 1929), glomerulitis (Coen and D'Ajutolo, 1888), and interstitial nephritis (Oliver, 1914).

It was hoped that the introduction of the clearance methods into the functional diagnosis of renal disease would throw more light on kidney trouble due to lead. However, the results obtained were again divergent. Crepet, Chiesura, and Gobbato (1953) concluded that renal lesions due to lead manifested themselves either in changes of the filtration membrane or in decreased intrarenal blood circulation brought about by a spasm of afferent arterioles. Radulescu, Dinischiotu, Maugsch, Ionescu, and Teodorescu-Exarcu (1957) observed a diminished filtration rate during attacks of lead colic, which they ascribed, at least in part, to interstitial oedema and diminished intrarenal blood circulation. In severe poisoning they assumed that interstitial nephritis was produced, as a result of increased permeability of blood vessels.

A number of Italian writers (Aiello, 1931; Micheli, 1935; Izar, 1941; Vigliani, 1950) favour the idea that lead has a primary vascular effect. Repeated angiospasm can in the end produce organic lesions, from fibrinoid necrosis of the arteries to the contracted nephrosclerotic kidney (Rizzo and Sbertoli, 1956; Baldi and Sbertoli, 1957).

From these data it is concluded that modern writers, using up-to-date methods for the study of the kidney are also inclined to think, however different their results are, that renal lesions due to 
TABLE 1

AGE, SEX, AND DURATION OF EXPOSURE IN 53 CASES OF LEAD POISONING

\begin{tabular}{|c|c|c|c|c|c|c|c|c|c|c|c|c|c|c|c|c|c|c|c|c|}
\hline \multirow{3}{*}{ Age } & \multicolumn{20}{|c|}{ Duration of Exposure to Lead (years) } \\
\hline & \multicolumn{2}{|c|}{$<1$} & \multicolumn{2}{|c|}{$1-2$} & \multicolumn{2}{|c|}{$3-4$} & \multicolumn{2}{|c|}{$5-9$} & \multicolumn{2}{|c|}{$10-14$} & \multicolumn{2}{|c|}{ 15-19 } & \multicolumn{2}{|c|}{$20-24$} & \multicolumn{2}{|c|}{$25-29$} & \multicolumn{2}{|c|}{$30-35$} & \multicolumn{2}{|c|}{ Unknown } \\
\hline & $\mathbf{M}$ & $\mathbf{F}$ & $\mathbf{M}$ & $\mathbf{F}$ & $\mathbf{M}$ & $\mathbf{F}$ & $\mathbf{M}$ & $\mathbf{F}$ & $\mathbf{M}$ & $\mathbf{F}$ & $\mathbf{M}$ & $\mathbf{F}$ & $\mathbf{M}$ & $\mathbf{F}$ & $\mathbf{M}$ & $\mathbf{F}$ & $\mathbf{M}$ & $\mathbf{F}$ & $\mathbf{M}$ & $\mathbf{F}$ \\
\hline $\begin{array}{l}20= \\
25= \\
30= \\
35= \\
40= \\
45= \\
50= \\
55-60\end{array}$ & $\begin{array}{l}5 \\
4 \\
1 \\
1 \\
- \\
- \\
- \\
- \\
\end{array}$ & $\begin{array}{l}\overline{1} \\
\overline{-} \\
\bar{z} \\
\overline{-}\end{array}$ & $\begin{array}{l}4 \\
4 \\
2 \\
1 \\
1 \\
1 \\
- \\
- \\
\end{array}$ & $\begin{array}{l}= \\
\overline{-} \\
\overline{-} \\
\overline{-}\end{array}$ & $\begin{array}{l}\overline{5} \\
1 \\
1 \\
- \\
= \\
-\end{array}$ & $\begin{array}{l}\overline{-} \\
\overline{1} \\
\overline{1} \\
\overline{-} \\
\overline{-}\end{array}$ & $\begin{array}{l}- \\
\overline{1} \\
1 \\
1 \\
\overline{1} \\
1\end{array}$ & $\begin{array}{l}- \\
\overline{-} \\
\overline{-} \\
\overline{-} \\
\overline{-}\end{array}$ & $\begin{array}{l}- \\
- \\
\overline{1} \\
1 \\
- \\
- \\
-\end{array}$ & $\begin{array}{l}- \\
\overline{1} \\
- \\
= \\
-\end{array}$ & $\begin{array}{l}\bar{z} \\
\bar{z} \\
\bar{z} \\
\overline{-} \\
\end{array}$ & $\begin{array}{l}- \\
- \\
\overline{-} \\
- \\
- \\
-\end{array}$ & $\begin{array}{l}\overline{-} \\
\overline{-} \\
\overline{-} \\
\overline{1} \\
-\end{array}$ & $\begin{array}{l}- \\
- \\
- \\
- \\
- \\
- \\
-\end{array}$ & $\begin{array}{l}\bar{z} \\
\bar{z} \\
\bar{z} \\
\bar{z} \\
\bar{z}\end{array}$ & $\begin{array}{l}- \\
- \\
- \\
- \\
- \\
- \\
-\end{array}$ & $\begin{array}{l}\overline{-} \\
\overline{-} \\
\overline{1} \\
\overline{-}\end{array}$ & $\begin{array}{l}\bar{z} \\
\bar{z} \\
\bar{z} \\
\bar{z}\end{array}$ & $\begin{array}{l}\overline{-} \\
\overline{1} \\
\overline{1} \\
1 \\
2 \\
-\end{array}$ & $\begin{array}{l}1 \\
1 \\
1 \\
\overline{1} \\
- \\
\overline{-}\end{array}$ \\
\hline $\begin{array}{c}33 \cdot 9 \\
\text { (average) }\end{array}$ & 11 & 1 & 13 & - & 7 & 2 & 5 & - & 2 & 1 & - & - & 1 & - & - & - & 1 & - & 5 & 4 \\
\hline
\end{tabular}

lead are possible. This has also been proved by biochemical studies (Dolowitz, Fazekas, and Himwich, 1937) and the study of enzyme dysfunction (Goldblatt and Goldblatt, 1956) and selective aminoaciduria (Clarkson and Kench, 1956; Wilson, Thomson, and Dent, 1953; Granati and Scavo, 1957) appearing in the course of lead poisoning.

We undertook the investigations now described in order to obtain more evidence about the effect of lead upon the kidney. We also wished to explain the cause of such great differences of opinion about the mechanism of the action of lead on the kidney.

\section{Material and Methods}

In the course of the past five years we have had under observation 53 patients suffering from lead poisoning. Their age, sex, and duration of exposure are given in Table 1.

Forty-four patients (40 men and four women) suffered from occupational lead poisoning (manufacture of electric accumulators and white lead, and the lead-glazing of earthenware). Lead intoxication in nine patients (five men and four women) was due to the use of leadglazed pottery for household purposes. Two patients with occupational saturnism (lead-glazing) also used lead-glazed pottery in their households, thus combining two sources of poisoning.

Lead-glazed pottery as a source of lead poisoning in Yugoslavia has been described by Beritič and Djurić (1956). It is well known that such pottery is used in the villages for such purposes as milk fermentation, pickling of vegetables, and wine and brandy preparation.

The period of occupational exposure to lead in the patients observed varied from two months to 35 years. Only two patients had a longer exposure than 14 years (20 and 35 years respectively).

In the cases of non-occupational lead poisoning (due to the household use of lead-glazed pottery), it was impossible to obtain an accurate estimate of the duration of exposure; the contamination was generally long and of varied intensity dep $\cong$ ding upon such factors as the season and the $p \mathrm{H}$ of the pottery contents.
Lead poisoning was divided into the types described by Johnstone (1948).

Stippled cells were determined by the Hamel method (1900) in all patients.

Reticulocytes were also determined in all patients. A modified Wolfer method was used (Schudel, 1938).

Lead in blood analyses were made in 44 patients by the modified dithizone method (Weber, Voloder, and Vouk, 1952).

Urinary porphyrins were determined by the modified Fisher method (Weber and Ruždić, 1951); this method was used in 44 patients.

All these analyses were made immediately after the admission of each patient to hospital.

Urine analyses were made of all patients on the first or second day of admission.

The urine concentration test was carried out in 21 patients by the modified Fishberg method (Fishberg, 1939) as follows: the evening meal contained no liquid; no fluid was consumed from 6 p.m. to 6 a.m. Urine specimens were taken before getting up, at 6, 7, and 8 a.m. The normal specific gravity for this test was taken as 1,026 or more.

The phenol red test was carried out in 33 patients by the Möller method (Möller and Rex, 1952). The excretion rate was determined after 15 minutes. Normal values: $36 \%$ or more.

Urea clearance was determined in 35 patients. Van Slyke's method (McIntosh, Möller, and Van Slyke, 1928) was used. A value of $70 \%$ or more was considered normal.

Blood urea was determined on the first, second, or third day of admission by the urease method after King (King, 1953). Normal values: up to $40 \mathrm{mg}$. $/ 100 \mathrm{ml}$.

The concentration test, phenol red test, and urea clearance test were not undertaken routinely, but were carried out on most patients at various stages of their disease.

Blood pressure was measured on the first day of admission. Normal values: up to $140 / 90 \mathrm{~mm}$. $\mathrm{Hg}$. 


\section{Results}

Table 2 gives the types of poisoning, and the laboratory and toxicological findings pointing to the diagnosis of lead poisoning.

The results of the renal function tests and blood pressure findings are summarized in Table 3 . The results of repeated analyses are not indicated in this Table.

In Table 4 particulars are given of 27 patients in whom at least one of the tests indicated some pathological changes. The results of repeated analyses are not indicated.

Urine analysis. - In 50 patients urine findings remained normal in repeated examinations carried out at intervals of four to five days during the course of treatment.

Case 1 (Table 4) with pathological urine findings suffered from exudative pleurisy also, which persisted when clinical symptoms of lead poisoning had disappeared. Two years later he was readmitted to hospital with manifest lead intoxication; the urine findings were then repeatedly normal.

Case 2 had repeatedly pathological urine findings in the course of treatment.

Case 3 was readmitted to hospital 10 months after his first treatment, owing to clinically manifest lead poisoning. This time, contrary to the first, the urine analysis was abnormal (albuminuria, erythrocytes, leucocytes, and granular and hyaline casts in the sediment), and remained so three years later when he was again admitted to hospital and treated for lead poisoning.

Blood urea.-In five patients with increased blood urea values in the first few days of treatment (Cases 5, 13, 25, 26, and 27) the tests repeated five to six days later gave normal values.

In Case 2 blood urea values were increased throughout the treatment.

In Case 3 the increased blood urea values became normal in seven days; 10 months later, owing to exacerbation of lead poisoning, he was again in hospital for treatment, showing temporary increase of blood urea values. However, during his third
TABLE 2

CASES OF LEAD POISONING: TYPE AND LABORATORY FINDINGS

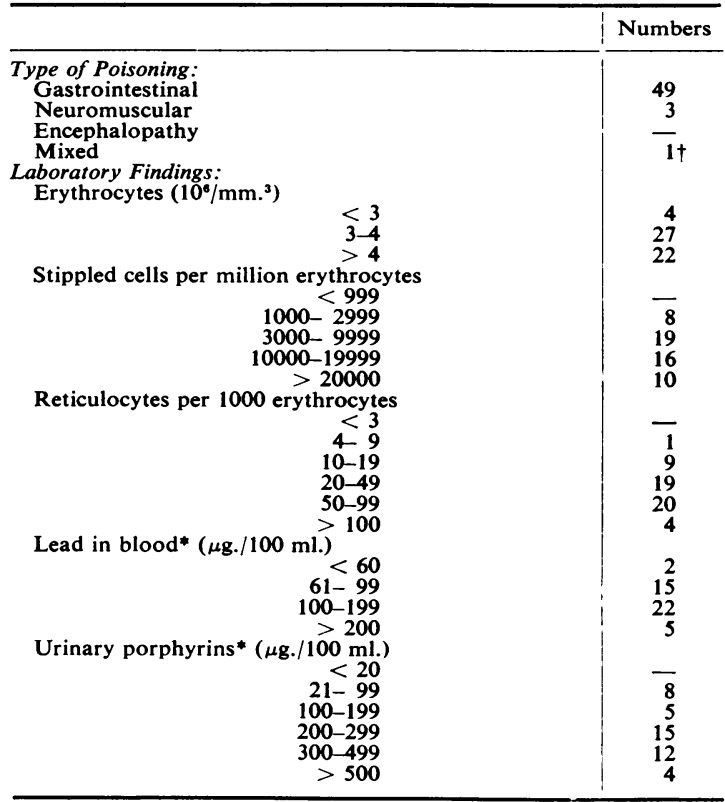

27 cases had a lead line on the gums.

* 44 cases.

$\dagger$ The mixed case was a combined gastrointestinal and encephalopathy type.

stay in hospital three years later the blood urea values were always raised (140-160 mg./100 ml.).

Blood pressure.-In two (Cases 4 and 24) out of four patients with hypertension (Table 4) blood pressure became normal in five and 10 days respectively.

The blood pressure of Case 2 remained high throughout the whole of his stay in hospital.

Case 5 also remained hypertensive throughout his stay in hospital. At subsequent check-up admissions to hospital two and three and a half years later the blood pressure was also raised $(195 / 105 \mathrm{~mm}$. $\mathrm{Hg})$.

The blood pressure of Case 3 was normal during his first admission, but was increased at the time of

TABLE 3

RESULTS OF THE RENAL FUNCTION TESTS AND BLOOD PRESSURE FINDINGS

\begin{tabular}{|c|c|c|c|c|c|c|c|c|c|c|c|}
\hline \multicolumn{2}{|c|}{ Urine } & \multicolumn{2}{|c|}{ Blood Urea } & \multicolumn{2}{|c|}{$\begin{array}{l}\text { Urea Clearance } \\
\text { Test }\end{array}$} & \multicolumn{2}{|c|}{$\begin{array}{c}\text { Urine Concentration } \\
\text { Test }\end{array}$} & \multicolumn{2}{|c|}{ Phenol Red Test } & \multicolumn{2}{|c|}{ Blood Pressure } \\
\hline $\mathbf{N}$ & $\mathbf{P}$ & $\mathbf{N}$ & $\mathbf{P}$ & $\mathbf{N}$ & $\mathbf{P}$ & $\mathbf{N}$ & $\mathbf{P}$ & $\mathbf{N}$ & $\mathbf{P}$ & $\mathbf{N}$ & $\mathbf{P}$ \\
\hline 51 & $2^{*}$ & 46 & 7 & 16 & 19 & 13 & 8 & 12 & 21 & 49 & 4 \\
\hline
\end{tabular}

$\mathbf{N}=$ normal. $\mathbf{P}=$ pathological.

* One case with proteinuria (opalescence), the sediment containing erythrocytes and leucocytes; and one case with proteinuria + , the se diment containing granular casts. 
TABLE 4 PARTICULARS OF 27 PATIENTS IN WHOM AT LEAST ONE OF THE TESTS INDICATED SOME PATHOLOGICAL

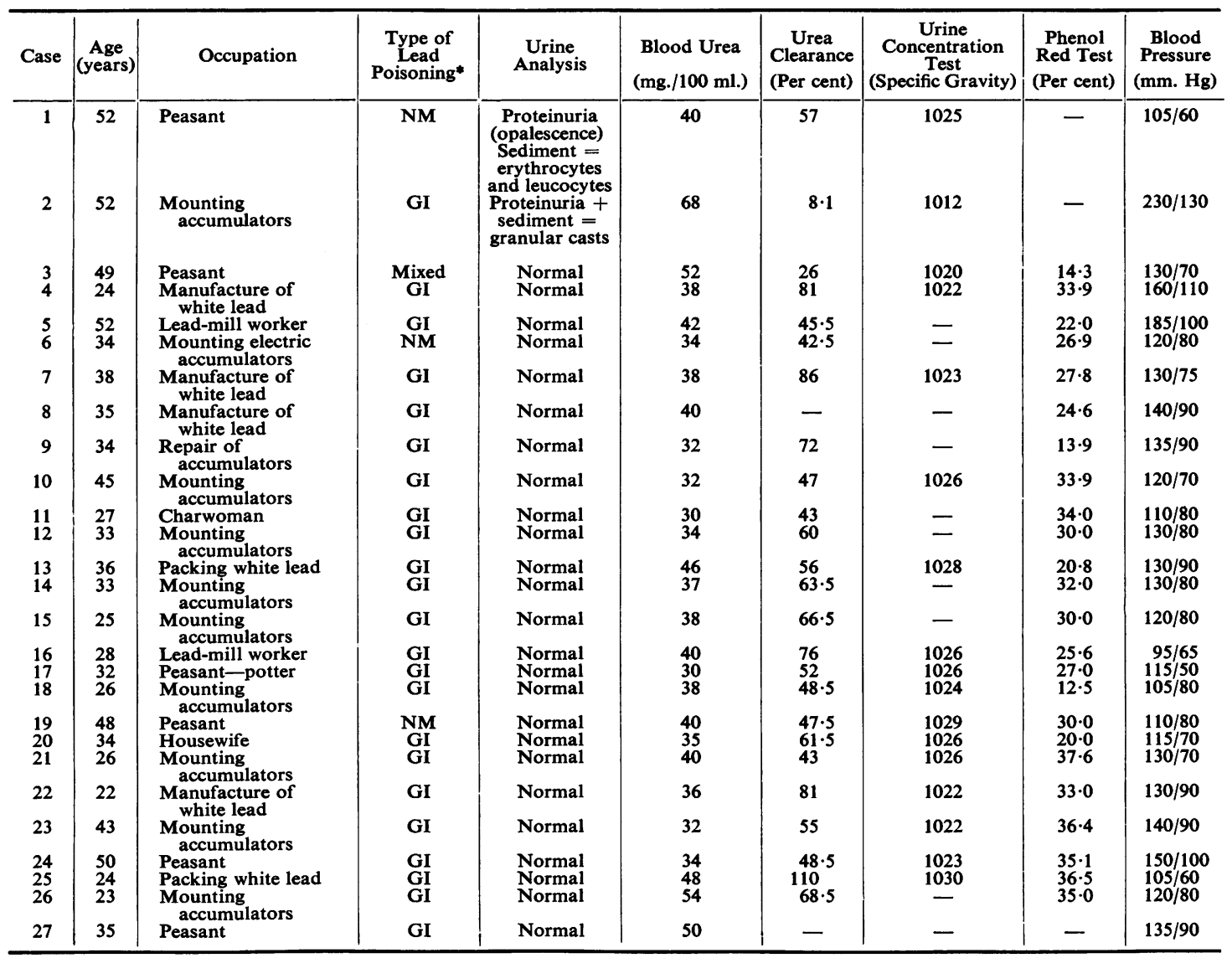

*NM $=$ neuromuscular, $\mathbf{G I}=$ gastrointestinal.

his second stay in hospital 10 months later, and became permanently raised by the time of his third stay in hospital after a lapse of three years.

Urine concentration test.-This test indicated pathological changes in eight out of 21 cases examined; it was repeated in a few cases only. The test was repeated in Case 1 whose urine concentration capacity during his first treatment increased to 1,025 , and who was readmitted to hospital for treatment for lead poisoning two years later. The results of the urine concentration tests carried out during this second admission are shown in Fig. 1.

The urine concentration capacity of Case 3 in the course of his first stay in hospital increased to 1,020. It only went up to 1,012 three years later, when he was in hospital again owing to manifest lead intoxication.

Phenol red test.-The phenol red test gave abnormal findings in 21 out of 33 patients examined, and was repeated in certain cases. Fig. 2 shows the results of the phenol red test in Case 1 during his second treatment for lead poisoning, two years after the first.

Case 3 repeatedly had decreased phenol red test values after 10 months and again after three years. They were $14.3 \%$ (Table 4 ) during his first stay in hospital and $18.3 \%$ and $16 \%$ respectively on subsequent admissions.

Case 5 again showed decreased phenol red excretion capacity $(11.6 \%$ and $24.3 \%$ respectively) when examined at routine follow-up after two and 
three and a half years, although no symptom of lead poisoning was present.

Urea clearance.-Out of 19 patients with abnormal urea clearance tests (35 patients examined in all) only Case 3 had markedly decreased clearance values at subsequent examinations $(39.3 \%$ after 10 months, $24 \%$ after three years). In Case 24 urea clearance was $48.5 \%$ (Table 4 ) on the seventh day of treatment and $74 \%$ on the 33rd day. In Case 5, on his first admission for lead intoxication, urea clearance was $45.5 \%$ (Table 4) and after three and a half years $70 \%$.

In Table 4, certain results such as those in Case 25 (blood urea $48 \mathrm{mg} . / 100 \mathrm{ml}$. and urea clearance $110 \%$ ) and in Case 26 (blood urea $54 \mathrm{mg} . / 100 \mathrm{ml}$., urea clearance $68.5 \%$ ), may appear inconsistent at first sight, but they were obtained at different times; thus in Case 25 blood urea was determined on March 15,1956 and urea clearance 13 days later, when the blood urea had returned to normal $(23.4 \mathrm{mg}$./ $100 \mathrm{ml}$.). There were similar differences in the dates of examination of Case 26.

Case 2 died of uraemia two years after leaving hospital. No autopsy was performed.

Case 3 died during his third stay in hospital. The clinical picture suggested uraemia. Histological examination of the kidney revealed severe tubular lesions with degenerative changes particularly pronounced in the proximal parts of the proximal convoluted tubules. The epithelium of the loops of Henle remained almost completely unaffected. The capsules of some glomeruli were slightly thickened, with patchy hyalinization, while the glomeruli in the subcapsular region were completely obliterated and replaced by hyaline tissue. In the larger intrarenal arteries the intima was thickened, the lumen narrowed, and some sclerotic changes were observed. Small arteries, particularly in the subcapsular region, were hyalinized. The concentration of lead in the kidney was $705 \mu \mathrm{g} . / 100 \mathrm{~g}$. of fresh kidney, in the liver $1,220 \mu \mathrm{g} . / 100 \mathrm{~g}$., and in the spleen $482 \mu \mathrm{g} . / 100 \mathrm{~g}$.

\section{Discussion}

On the basis of the results obtained, three facts should be pointed out before any detailed comment is made:

(1) There was a very small number of proved cases of organic nephropathy, and the very small number of pathological urinary findings conflicted with the large number of pathological renal function test values.

(2) Only three out of the 53 patients had a persistently raised blood pressure.

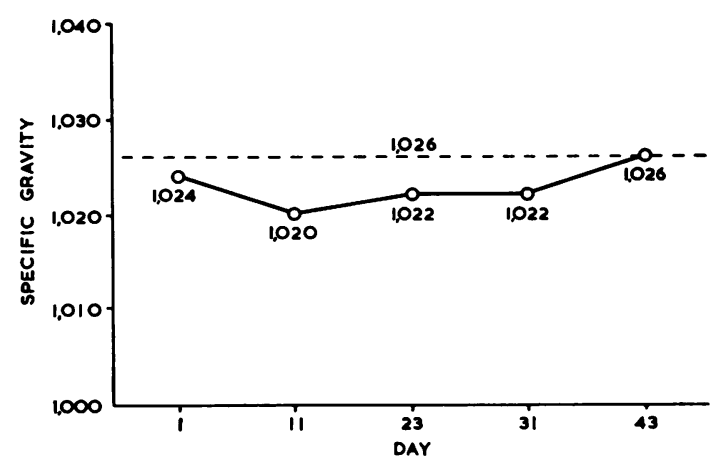

Fig. 1.-Case 1: Urine concentration test results during the second treatment in hospital.

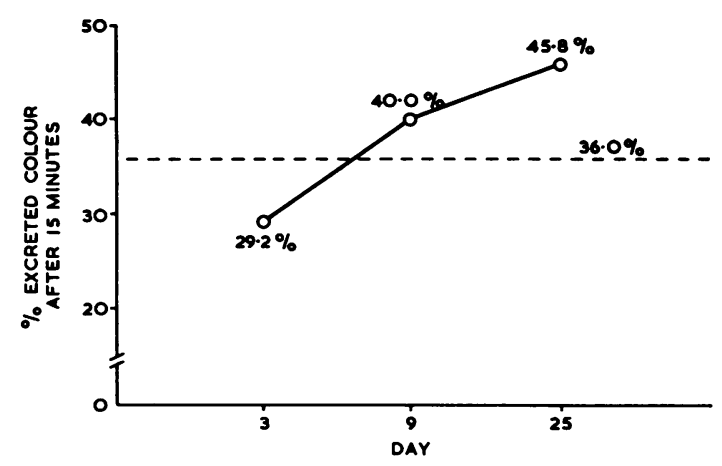

FIG. 2.-Case 1: Phenol red test results during the second treatment.

(3) Some pathological changes returned to normal during the natural course of the disease.

Urine analysis.-Out of three cases with pathological urine findings two were the severest cases in the whole group (Cases 2 and 3), both with well-marked nephropathy; they had had long exposure to lead-22 and 35 years respectively. Case 2 was treated in hospital for lead poisoning on one occasion only, but his history showed that in the course of his exposure to lead he had had several attacks of colic. On his admission to hospital he already had renal insufficiency and, as has been mentioned earlier, died of uraemia two years later. In Case 3 urine abnormalities appeared late, only during his second stay in hospital. Three years later he died of uraemia. It should be pointed out that this patient (a potter !) had been continuously exposed to lead between his admissions to hospital. In the third patient (Case 1) pathological urine findings could not be ascribed to the effect of lead with certainty, as active exudative pleurisy had developed which might have produced albuminuria; in the course of follow-up examinations, when he had recovered from pleurisy, the urine findings 
became repeatedly normal, although exposure to lead continued and brought about repeated manifest intoxication. Thus, pathological urine findings, which may have been the result of lead action, were shown to have occurred only in two patients suffering from severe lead nephropathy. These cases confirm the opinion of some writers (Lane, 1949; Vigliani, 1950) quoted above, according to whom severe irreversible nephropathy can be expected to occur in persons with prolonged and intense exposure to lead who have frequently had repeated manifest lead intoxication.

The absence of proteinuria in patients who showed no symptoms of permanent organic kidney lesions is also in accord with the observations of other writers (Radulescu et al., 1957).

In spite of the other pathological findings and a comparatively large number of abnormal renal function test values, the negative urine findings argue decisively against the presence of glomerulitis and other more pronounced lesions of filtration membrane permeability. Thus, on the basis of our observations, the writers (Crepet et al., 1953) who consider glomerulitis and lesions of filtration membrane permeability to indicate the so-called nephropathia saturnina cannot be supported.

Blood pressure.-No special comment seems to be necessary about the temporary increase of blood pressure in the phase of manifest lead intoxication. This is a well-known finding believed to be due to the spastic effect of lead on arterial muscle fibres. The fact that only two of our patients showed temporarily raised blood pressure may seem surprising, but this finding would probably have been recorded more frequently if we had had the opportunity to observe the patients from the onset of poisoning.

Of three patients with persistently raised blood pressure, two had severe nephropathy. From the results already given it is seen that in Case 3 the blood pressure rose as the kidney trouble worsened. The third patient with persistently raised blood pressure (Case 5) had no abnormal urine findings. As is seen from Table 4, during his first stay in hospital on account of lead intoxication, the phenol red and urea clearance tests gave diminished values, while the blood pressure was $185 / 100$. During the next two years he was not exposed to lead, but the blood pressure of $180 / 100$ persisted. At this time the urine analysis and the concentration and urea clearance values were normal. Only the result of the phenol red test was worse than that obtained during his first admission. On the third check-up a year and a half later the results were the same. The results of the renal function tests in this patient were identical with those in non-complicated essential hypertension. It cannot be stated that the arterial hypertension and lead exposure in this case (duration of exposure eight years, with repeated attacks of lead colic) were related, but neither can this assumption be rejected on the evidence available.

On the basis of these observations it is suggested that a persistent increase of blood pressure in patients suffering from lead poisoning occurs very seldom. It is usually associated with organic nephropathy which indicates hypertension of a nephrogenic type.

Blood urea.-The permanently increased blood urea levels in two severe cases of nephropathy with renal insufficiency are easy to understand. Mild, temporary azotaemia, observed in some of our patients, has been described in association with lead poisoning (Bell et al., 1925; Radulescu et al., 1957; Hadengue and Collin, 1951). It appears that the earlier the blood urea is measured in a case of lead poisoning, the more likely is azotaemia to be found. In our investigations the blood urea was measured at the beginning of treatment, but had it been examined at the onset of intoxication, i.e. had the patients come to hospital earlier, the number of pathological findings would probably have been greater. As lead intoxication advances, the values of $\mathrm{N}$-substances in the blood return to normal in the natural course of events.

Since patients with temporary azotaemia had normal urine findings, there can be no question of any serious glomerular or vascular renal lesions in these cases. As there were no symptoms of the so-called extrarenal azotaemia, some functional intrarenal lesion should be assumed. It may have been a spasm of afferent glomerular arterioles with consequent diminution of the glomerular filtration rate together with temporary azotaemia. The susceptibility of afferent arterioles to lead has been described several times (Crepet et al., 1953; Radulescu et al., 1957; Crepet and Gobbato, 1954).

Urine concentration test.-A diminished urine concentration capacity was frequently found in our patients. It indicates lesions of the distal parts of the tubules, due either to direct toxic effect of lead (Flury, 1934; Beintker, 1929; Radulescu et al., 1957; Clarkson and Kench, 1956; Wilson et al., 1953) or to a reduced intrarenal circulation with consequent hypoxia.

Diminished concentration in the two severe nephropaths seems easy to understand. In other cases there was a mild, probably reversible, diminution of urine concentration (Fig. 1). 
Phenol red test. - On the basis of this comparatively inconclusive test no definite conclusion could be drawn concerning selective renal lesions. The results of this test reflect both the excretion capacity of the proximal parts of the tubules and the condition of the intrarenal circulation.

Our investigations have led us to the conclusion that the determination of the amount of phenol red excreted in 15 minutes can reveal more undefined tubular lesions than tests carried out after a longer interval, as in the former case the contact of the dye with the tubular epithelium is shorter.

In Cases 2 and 3 the abnormal phenol red test values can be understood. In Case 5 a reduced phenol red excretion was a permanent functional abnormality. This is assumed to be due to some defect in the intrarenal circulation, as is typical of arterial hypertension.

The repeated phenol red tests in Case 1 (Fig. 2) suggest that in the natural course of the disease abnormal findings may also return to normal (except in cases of irreparable organic renal lesions or persistent arterial hypertension).

The unusual combination of results obtained in the examinations of renal function in Case 24 , i.e. reduced urine concentration capacity, reduced glomerular filtration rate, but normal phenol red test values can be explained by the fact that the phenol red test was carried out eight days after the two other tests, when renal function may have returned to normal.

These conclusions may seem unjustifiable with regard to the "non-selectivity" of the phenol red test. However, it should be remembered that in addition to a generally recognized diminution of intrarenal circulation rate in lead poisoning (Crepet et al., 1953; Radulescu et al., 1957; Baldi and Sbertoli, 1957), tubular lesions have also been proved to occur (Flury, 1934; Beintker, 1929; Radulescu et al., 1957). These lesions were the dominant feature of the post-mortem findings in Case 4. The selective determination of the excretion capacity of the tubules by para-aminohippuric acid, carried out by various investigators, has also shown that tubular lesions may occur in lead poisoning (Crepet et al., 1953; Rizzo and Sbertoli, 1956).

Urea clearance.-Among patients with abnormal urea clearance values, the lowest were found in two uraemic nephropaths with abnormal urine findings. In other patients the clearance values were slightly or moderately decreased, urine findings persistently normal, while the blood urea values were slightly increased in some patients at the beginning of treatment. We have assumed that the decreased urea clearance values in most patients were due to reduced intrarenal circulation brought about by spasm of afferent arterioles. A decreased filtration rate in lead poisoning has been observed by other writers (Crepet et al., 1953; Rizzo and Sbertoli, 1956). The earlier the examination takes place in the course of intoxication, the more often changes in glomerular filtration rate are observed. Radulescu et al. (1957) found diminished glomerular filtration rates in half of 82 patients with lead poisoning. When examinations were undertaken during an attack of colic, no fewer than $70 \%$ of the patients showed decreased glomerular filtration rates.

The results of repeated urea clearance tests suggested that the decreased filtration rate was temporary. Persistence or development of glomerular filtration lesions in repeated examinations argue in favour of an organic renal lesion (e.g. Case 3).

Most of our patients appear, therefore, to have had decreased glomerular filtration values due to temporary functional disturbances in the intrarenal circulation.

The evidence obtained in this study shows that in most cases the effect of lead upon the kidney manifests itself as reversible changes in the intrarenal circulation and as temporary, slight tubular lesions. These lesions sometimes occurred together. However, owing to rapid changes in these lesions a more thorough insight into their nature can be obtained only by repeated functional examinations in the various phases of lead poisoning, taking into account also the time at which the individual analyses are carried out. By neglecting this point the apparently disparate results of certain renal function tests performed at intervals may obscure the whole picture, and this may indeed have been the cause of many contradictory statements recorded so far on this problem.

\section{Conclusion}

On the basis of observations on the effect of lead upon the kidney in 53 patients with proved lead poisoning we have come to the conclusion that this condition can cause renal damage. The changes observed varied widely and we could not confirm the existence of any condition that might be called " nephropathia saturnina". The renal lesions due to the toxic effect of lead may be either functional or anatomical.

Permanent organic changes in the form of chronic progressive diffuse nephropathy with transition into nephrosclerosis and uraemia have been observed only in two out of 53 patients. It should be pointed out that these two patients were just those with the longest and most severe exposure to lead; they were 
cases of repeated poisoning. In 23 of the remaining 51 patients various functional renal lesions tending to normalize were observed, without abnormal urine findings.

The data presented are compatible with the explanation referred to in the literature that the partial impairment of renal function is brought about by disordered intrarenal circulation resulting from the spastic effect of lead on the intrarenal blood vessels, and direct toxic or indirect hypoxic effect of lead on the tubules. The occurrence of transitory azotaemia accompanied by normal urine findings may also be explained in this way.

Apart from two cases of temporarily increased blood pressure in the phase of acute poisoning, permanent hypertension appeared to correspond with the development of organic nephropathy. In one case of persistently raised blood pressure of the type of essential hypertension a causal link between the effect of lead and the hypertension could not be proved.

In assessing the results of renal function tests attention should be paid to when the tests are made, both as regards the phase of the disease and the intervals between the tests themselves. This is important as the pathological changes do not occur simultaneously nor at the same rate of progress, so that at one moment a certain functional lesion may be present, while at the next moment a different lesion may dominate the picture.

\section{REFERENCES}

Aiello, C. (1931), Med d Lavoro, 22, 145

Aaldi, C. (1931). Med. d. Lavoro, 22, 145. 533

Battaglia, F. (1927). Policlinico, Sez. med., 34, 154.

Battaglia, F. (1927). Policlinico, Sez. med.

Beintker, K. (1929). Med. Welt, 3, 1292.
Belknap, E. L. (1936). J. industr. Hyg., 18, 380.

Belknap, E. L. (1936). J. industr. Hyg., 18, 380. . (1925). Lancet,

Bell, W. B., 793 .

Beritić, T., and Djurić, D. (1956). Higijena, 8, 12.

Brogsitter, M., and Wodarz, H. (1922). Dtsch. Arch. klin. Med., 139, 129 .
Cantarow, A. and Trumper, M. (1944). Lead Poisoning. Williams and Wilkins, Baltimore.

Cilento R W (1932) Commonwealth of Australia: Interim Report on an Official Inquiry into Chronic Nephritis of Queensland on an Official Inquiry into Chronic Nephritis of
with Special Reference to Plumbism in Children.

Clarkson, T. W., and Kench, J. E. (1956). Biochem. J., 62, 361

Coen, E., and D'Ajutolo, G. (1888). Beitr. path. Anat., 3, 449.

Crepet, M., Chiesura, P., and Gobbato, F. (1953). Fol. Med. (Napoli), 36, 181

Dol, and Gobbato, F. (1954). Med. d. Lavoro, 45, (1937). J. industr. Hyg., 19, 93 .

Fishberg, A. M. (1939). Hypertension and Nephritis, 4th ed. Lea and Febiger, Philadelphia.

Flury, F. (1934). In Handbuch der experimentellen Pharmakologie, ed. A. Heffter, Vol. 3, Part 3, p. 1575. Springer, Berlin.

Gayler, J. (1887). Zur Histologie der Schrumpfniere nach chronischer Bleivergiftung. Dissertation, Tübingen.

Goldblatt, M. W., and Goldblatt, Judith (1956). In Industrial Medicine and Hygiene, ed. E. R. A. Mereweather, Vol. 3 Butterworth, London.

Granati, A and Scavo, D. (1957). Fol. Med. (Napoli), 40, 832.

Greenfield, I and Gray I (1950). Amer. Heart J., 39, 430

Greentield, 1 , and Gray, I. (1950). Amer. Heart J., 39, 430. 12,561

Hamel, C. (1900). Dtsch. Arch. klin. Med., 67, 357.

Henderson, D. A. (1954). Austr. Ann. Med., 3, 219.

Henderson, D. A. (1954).

(1955). Ibid., 4, 163. Med. J. Aust., 1, 377.

, and Inglis, J. A. (1957). Aust. Ann. Med., 6, 145

Hoffa, A. (1883). Ueber Nephritis saturnina. Dissertation, Wagner, Freiburg (Cited by Cantarow and Trumper, 1944).

Humperdinck, K. (1948) Aerztl. Forschung, 2, Part II, Referate, 119.

Izar, G. (1941). Gazz. Osp. Clin., 62, 295.

Johnstone, R. T. (1948). Occupational Medicine and Industrial Hygiene. Mosby, St. Louis.

Hygiene. Mosby, St. Louis. $31,183$.

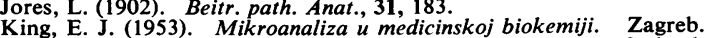
Trans. of Micro-analysis in Medical Biochemistry, 2nd ed. 1951. Churchill, London.

Lancereaux, E. (1881). Arch. gén. Méd., Ser. VII, 6, 641

Lane, R. E. (1949). Brit. J. industr. Med., 6, 125.

Leyden, E. (1883). Dtsch. med. Wschr., 19, 185.

Mayers, H. R. (1947). Occup. Med, 3, 77.

Mclintosh, J. F., Möller, E, and Van Slyke, D. D. (1928). J. clin. Invest., 6, 467.

Micheli, F (1935) Rass. Med Lav industr. 6, 11

Micheli, F. (1935). Rass. Med. Lav. industr., 6, 11. 103.

Möller, J., and Rex, W. (1952). Z. klin. Med., 150, 103.

Murray, R. E. (1939). Plumbism and chronic nephritis in young

people in Queensland. Serv. Publ. Dep. Hith Aust., No. 2.
Nye, L. J. J. (1933). Chronic Nephritis and Lead Poisoning. Angus and Robertson, Sydney.

Oliver, T. (1914). Lead Poisoning. Lewis, London.

Radulescu, I. C., Dinischiotu, G. T., Maugsch, C., Ionescu, C., and Teodorescu-Exarcu, I. (1957). Arch. Mal. prof., 18,125.

Rizzo, A and Sbertoli, (1956). Med. d. Lavoro, 47, 117

Schudel, L. (1938). Leitfaden der Blutmorphologie, 2nd ed. Thieme,

Ligliani, E. C. (1950). Med. d. Lavoro, 41, 105.

Vigliani, E. C. (1950). Med. d. Lavoro, 41, 105. Springer, Berlin.

Weber, K., and Ruždić, J. (1951). Experientia (Basel), 7, 354.

Weber, O. A., Voloder, K., and Vouk, V. B. (1952). Arh. Hig. Rada, $3,296$.

Wilson, Vera K., Thomson, M. L., and Dent, C. E. (1953). Lancet,

Wirtschafter, Z. T. (1933). Ohio St. med. J., 29, 771. 